\title{
RESPIRATORY HEALTH PROBLEMS IN ADOLESCENTS LIVING NEAR MAIN ROADS IN THE UPPER SILESIAN INDUSTRIAL ZONE, POLAND
}

\section{MICHAŁ SKRZYPEK ${ }^{1}$, MAŁGORZATA KOWALSKA ${ }^{2}$,JOANNA KASZNIA-KOCOT ${ }^{3}$, ELŻBIETA M. CZECH ${ }^{1}$, and EWA NIEWIADOMSKA ${ }^{1}$}

Medical University of Silesia, Katowice, Poland

${ }^{1}$ School of Public Health in Bytom, Department of Biostatistics

${ }^{2}$ Medical Faculty in Katowice, Department of Epidemiology

${ }^{3}$ School of Public Health in Bytom, Department of Epidemiology

\begin{abstract}
Objectives: This study explores the association between self-reported exposure to traffic-related air pollution and respiratory health symptoms, as well as lung functions and skin prick tests in adolescents living in the vicinity of main roads. Material and Methods: The data in the study were acquired using a cross-sectional study conducted between 2004-2005 in Chorzów (Silesia, Poland) among adolescents (N = 936) aged 13-15 years, attending junior high schools. Adverse respiratory health symptoms and exposure to traffic-related air pollution were determined on the basis of a questionnaire. Moreover, all children underwent spirometry and skin prick tests. Multivariable logistic regression with multiple imputation for missing data was used to assess the prevalence of adverse respiratory symptoms in relation to self-reported exposure to traffic-related air pollution, adjusted for socioeconomic and environmental factors. Results: Among respiratory tract diseases, asthma and allergic rhinitis associations were statistically significant $(\mathrm{OR}=2.16,95 \% \mathrm{CI}: 1.12-4.15$ and $\mathrm{OR}=1.69,95 \% \mathrm{CI}: 1.08-2.64$, respectively $)$. Likewise, among respiratory disorders, statistically significant associations were found in the case of wheezes and dyspnea attack $(\mathrm{OR}=1.58,95 \% \mathrm{CI}: 1.10-2.26$ and $\mathrm{OR}=2.39,95 \%$ CI: $1.56-3.66$, respectively), with respect to the vicinity of the main road. Living in the area with high traffic intensity was statistically significantly associated with a higher prevalence of asthma and wheezes (OR $=2.31,95 \%$ CI: $1.22-4.39$ and 1.48, 95\% CI: 1.09-2.01, respectively). The results obtained did not confirm the relationship between the adopted way of exposure to traffic-related air pollution and lung function indices or skin prick tests. Conclusions: Results of the study suggest that children living in the area with intense traffic are more likely to develop respiratory disorders. Moreover, the vicinity of a main road as well as traffic intensity could be suitable in assessing the relationship between road transport and potential health problems among exposed inhabitants. Int J Occup Med Environ Health. 2019;32(4):553-67
\end{abstract}

Key words:

lung volume measurements, respiratory diseases, adolescents, skin prick test, transportation, vehicles

Funding: this research was supported by the Medical University of Silesia in Katowice (grant No. KNW-1-184/N/5/0 entitled "The prevalence of allergic diseases in children living in Chorzów according to traffic-related ambient air pollution," grant manager: Michał Skrzypek, Ph.D.).

Received: March 27, 2018. Accepted: April 17, 2018.

Corresponding author: Michał Skrzypek, Medical University of Silesia, School of Public Health in Bytom, Department of Biostatistics, Piekarska 18, 41-902 Bytom, Poland (e-mail: mskrzypek@sum.edu.pl). 


\section{INTRODUCTION}

Data gathered by the WHO show that respiratory diseases remain one of the most important threats to health in Europe, especially among children [1]. Numerous publications suggest that adverse respiratory health effects in children are related to their exposure to ambient air pollution, especially in the urban environment [2-10]. There are many sources of outdoor air pollution in Europe (including the Silesian Agglomeration). The most important are vehicles, industry and power plants [11]. Moreover, residential heating by using coal furnaces during the winter season is another clear contributor [12].

Although Europe's air quality is slowly improving, fine particulate matter $\left(\mathrm{PM}_{2.5}\right)$ and nitrogen oxides $\left(\mathrm{NO}_{\mathrm{x}}\right)$ from vehicles remain a serious public health concern [13]. However, the relationship between traffic-related air pollution and health consequences has not been adequately explained. This may be due to either the use of different models of exposure, different populations studied (i.e., children or adults) or the main sources of pollution. There are several studies indicating the intense car traffic as a potential risk factor for respiratory diseases and disorders [14-22]. However, such a relationship was not confirmed by other studies [9,23-25]. In addition, one of the recent WHO reports on contaminated sites and public health has pointed out the co-occurrence of hazard related to industrial pollution and the increasing intensity of road transport [26].

The Silesian Agglomeration (the south part of Poland) is one of the post-industrial regions of Europe with a relatively high number of inhabitants and an increasing number of vehicles $[13,27]$. Recently published data suggest an increase in the prevalence of childhood asthma in the Silesian Agglomeration area [28].

The aim of this study was to assess the prevalence of respiratory diseases and disorders, as well as the sensitization and lung functions, in adolescents living in the vicinity of the main roads in Chorzów, the second most populated city in the Silesian Agglomeration, with almost 3500 inhabitants/ $/ \mathrm{km}^{2}$ [29].

\section{MATERIAL AND METHODS}

The data were obtained from a cross-sectional study of children's respiratory health and allergic diseases, conducted in 2004-2005 in Chorzów. Children aged 13-15 years, attending all junior high schools (gimnazjum), were invited to participate in the study $(\mathrm{N}=4520)$. The response rate among the participants was $25 \%(\mathrm{~N}=1130)$.

The research protocol used the following methods: a questionnaire interview, a medical examination, spirometry, and skin prick testing. The questionnaire, based on the International Study of Asthma and Allergies in Childhood (ISAAC) and the Central European Study of Air Pollution and Respiratory Health (PHARE/CESAR) programs, and validated by the Institute of Occupational Medicine and Environmental Health [30,31], was filled out by parents or legal guardians of the children involved in the study. Spirometry was performed by a fully trained researcher. Lung function measurements, including forced vital capacity (FVC), forced expiratory volume in $1 \mathrm{~s}\left(\mathrm{FEV}_{1}\right)$, percent predicted $\mathrm{FEV}_{1}$, peak expiratory flow (PEF), and mid-expiratory flow $\left(\mathrm{MEF}_{\mathrm{X}}\right)$ at $25-75 \%$ of FVC, were obtained with an autocalibrated ultrasonic flow-sensing spirometer (EasyOne, ndd Medical Technologies, Inc. Zurich, Switzerland).

Skin prick tests were carried out with the following allergens: cockroach (Blatella germanica), dogs' and cats' fur, mixed grass pollen, mixed weed pollen, tree pollen (Corylus avellana, Betula alba), moulds (Alternaria tenuis, Cladosporium herbarum, Aspergillus fumigatus), house dust and flour mites (Dermatophagoides pteronyssinus, Dermatophagoides farinae), as well as storage mites (Acarus siro, Tyrophaus putrecentiae, Lepioglyphus destructor), and histamine as positive and $0.9 \%$ sterile saline as negative control. The tests were interpreted within 15-20 min after they were performed. The positive result of the skin prick test was defined as a wheal $\geq 3 \mathrm{~mm}$ diameter [32]. 
The study was conducted with the approval of the Bioethical Committee of the Medical University of Silesia, No. NN-013-03/03. Among all the respondents, spirometry and skin prick tests were conducted on $961(85 \%)$ children. However, 25 records were eventually removed due to missing data representing exposure to traffic-related air pollution. Thus, the final database contained 936 records. The exposure assessment of traffic-related air pollution was based on responses to the following questions:

1. Describe the road near the place of your residence, with 7 possible response options: a highway, a main road in the city, a regional road between 2 cities, a main road in the city district, a main road in the housing estate, and a side road.

2. How often do cars pass by the road near the place of your residence, apart from the weekend, with 4 possible response options: never, rarely, frequently, and almost all day.

The authors defined 2 surrogates of exposure to trafficrelated air pollution, namely the higher exposure from the "main road" if the response was at least "a regional road between 2 cities" to the first question, and "high traffic intensity" if the response was "almost all day" to the second question. Such definitions of the surrogates of exposure are plausible because the previously published results confirmed the relationship between proximity to the road and elevated concentrations of particulate matter and ozone [33,34].

Adverse health effects in children were determined on the basis of responses to the questions on ever doctordiagnosed asthma, ever doctor-diagnosed spastic bronchitis, current (within last 12 months) and ever asthma medication use, current (within last 12 months) and ever chest wheeze, current (within last 12 months) and ever dyspnea attack, current (within last 12 months) and ever runny nose, current (within last 12 months) persistent cough, and ever doctor-diagnosed allergic rhinitis.

Categorical variables were presented as frequencies and percentages. Continuous variables were expressed as the mean and standard deviation (SD), or as median and quartiles. The assumption of normality was verified by the Shapiro-Wilk test. Categorical variables were compared using the $\chi^{2}$ test. The Student's t-test and the Mann-Whitney $U$ test were used to assess group differences for normally and non-normally distributed continuous variables, respectively. The association between traffic exposure and adverse health effects was analyzed by means of multivariable logistic regression.

The scope of the health effects analyzed by means of logistic regression included the following medical diagnosis: asthma and spastic bronchitis, wheezes, dyspnea attack, runny nose, and allergic rhinitis. The following confounders were controlled in the analysis: gender, body mass index (BMI), maternal employment, exposure to environmental tobacco smoke (ETS) at home, type of heating (coal-based or central), traces of moisture or moulds in the place of residence, and parental allergy. Age was intentionally omitted in the logistic regression because of the homogeneity of age (13-15 years old).

In order to minimize bias due to some missing data in the scope of the explanatory variables in the logistic regression model, multiple imputation under missing at random (MAR) assumption was used. The MAR assumption was checked with the "missingPattern" SAS macro [35]. The imputation technique was performed by means of the fully conditional specification (FCS) method. To evaluate parameter estimates of the logistic regression, 20 imputed data sets were used, while the number of burn-in iterations was set to 100 . Results of the logistic regression were expressed as the odds ratio (OR) with $95 \%$ confidence interval $(95 \%$ CI). The statistical significance level was set at $\alpha=0.05$ criterion. Statistical analyses were conducted using the SAS statistical software package, version 9.4 (SAS Institute Inc., Cary, North Carolina, USA).

\section{RESULTS}

According to the self-reported assessment of exposure to traffic-related air pollution, the vicinity to the main 


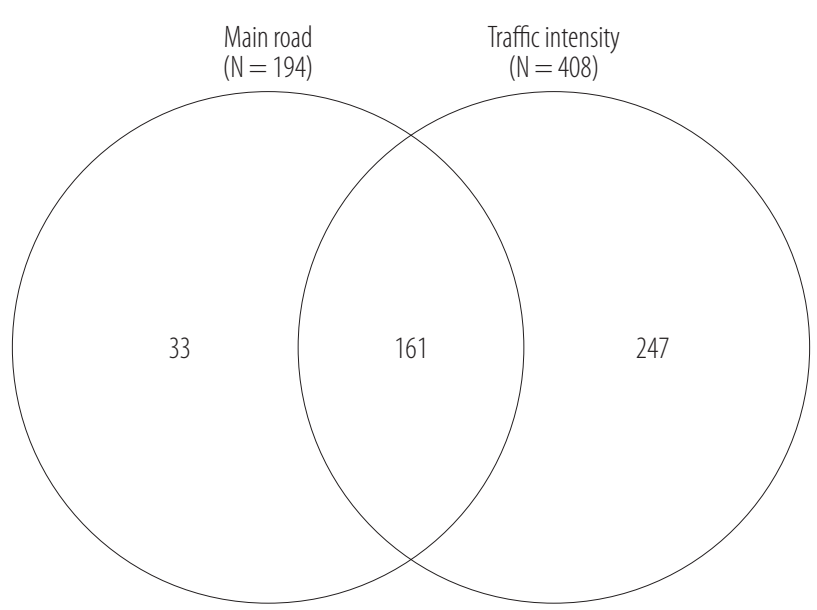

Figure 1. Children exposed to traffic-related air pollution, living in the Chorzów city, according to the defined surrogates of exposure in the cross-sectional study conducted in 2004-2005 in Chorzów (Silesia, Poland), involving adolescents ( $\mathrm{N}=936)$ aged 13-15 years, attending junior high schools - Venn diagram

road was the place of residence of $194(20.7 \%)$ children, while 408 (43.6\%) children lived in the area with high traffic intensity. The interaction between these 2 surrogates of exposure to traffic-related air pollution is presented in the Venn diagram (Figure 1).

Descriptive characteristics of the participants are presented separately in Table 1 for the 2 surrogates of exposure to traffic-related air pollution. There were slightly more girls (55.1\%) than boys in the studied group. Most of the children were from moderately educated families. Mothers of 51\% of the children completed at least high school education, and the majority of them were employed $(83.1 \%)$. Household smoking was significantly frequent $(65.6 \%)$ in the study group. Most of the houses where the children lived had coalbased heating $(60.8 \%)$, and the traces of moistures or moulds were present in half of them. A higher socio-economic status of parents was more common in the area with lower exposure to traffic-related air pollution, whereas coal-based heating and traces of moisture or mould were more frequent in the area with higher exposure to traffic-related air pollution. The prevalence of respiratory health problems in children and their association with self-reported exposure to traf- fic-related air pollution are shown in Table 2. The most frequent respiratory tract disorder in the study population was runny nose (> 40\%), while asthma was reported in $5 \%$ of the children. The analysis performed by the authors showed that respiratory health problems occurred more frequently in children living in the vicinity of a main road. Evidently, spastic bronchitis and runny nose were not statistically significant. Similarly, children living in the area with high traffic intensity often reported respiratory health problems, but statistically significant association was observed only for asthma, current and ever chest wheezes, dyspnea attack, ever runny nose, and current persistent cough.

Table 3 displays lung function and skin prick tests in children, and their comparison between the groups defined by self-reported exposure to traffic-related air pollution. The mean $\mathrm{FVC}, \mathrm{FEV}_{1}$ and percent predicted $\mathrm{FEV}_{1}$ amounted to $\mathrm{M} \pm \mathrm{SD}=3.62 \pm 0.721,3.19 \pm 0.621$ and $88.7 \pm 7.9 \%$, respectively. Interestingly, all the analyzed pulmonary function indices did not differ significantly between the exposed and unexposed group.

The authors also conducted sensitivity analysis, excluding children with prior asthma diagnosis and children with current asthma medication use. The obtained results did not differ from those presented here (data not shown). Almost half of the children (47.1\%) showed sensitization to at least 1 of the tested allergens (Table 3 ). The most frequent sensitization was to house dust mites $(30.9 \%)$, followed by flour mites $(26.6 \%)$ and grass pollen $(21.9 \%)$. Boys were more likely than girls to have positive skin prick tests only in the case of grass pollen $(25.7 \%$ vs. $18.8 \%$, respectively; $p=0.01)$ and flour mites $(30.2 \%$ vs. $23.6 \%$, respectively; $p=0.02$ ).

In addition, a comparison between the exposed and unexposed group did not reveal any statistically significant differences in the prevalence of sensitization, with 1 exception, namely the positive skin prick test to Cladosporium herbarum. Sensitivity to Cladosporium herbarum was more 


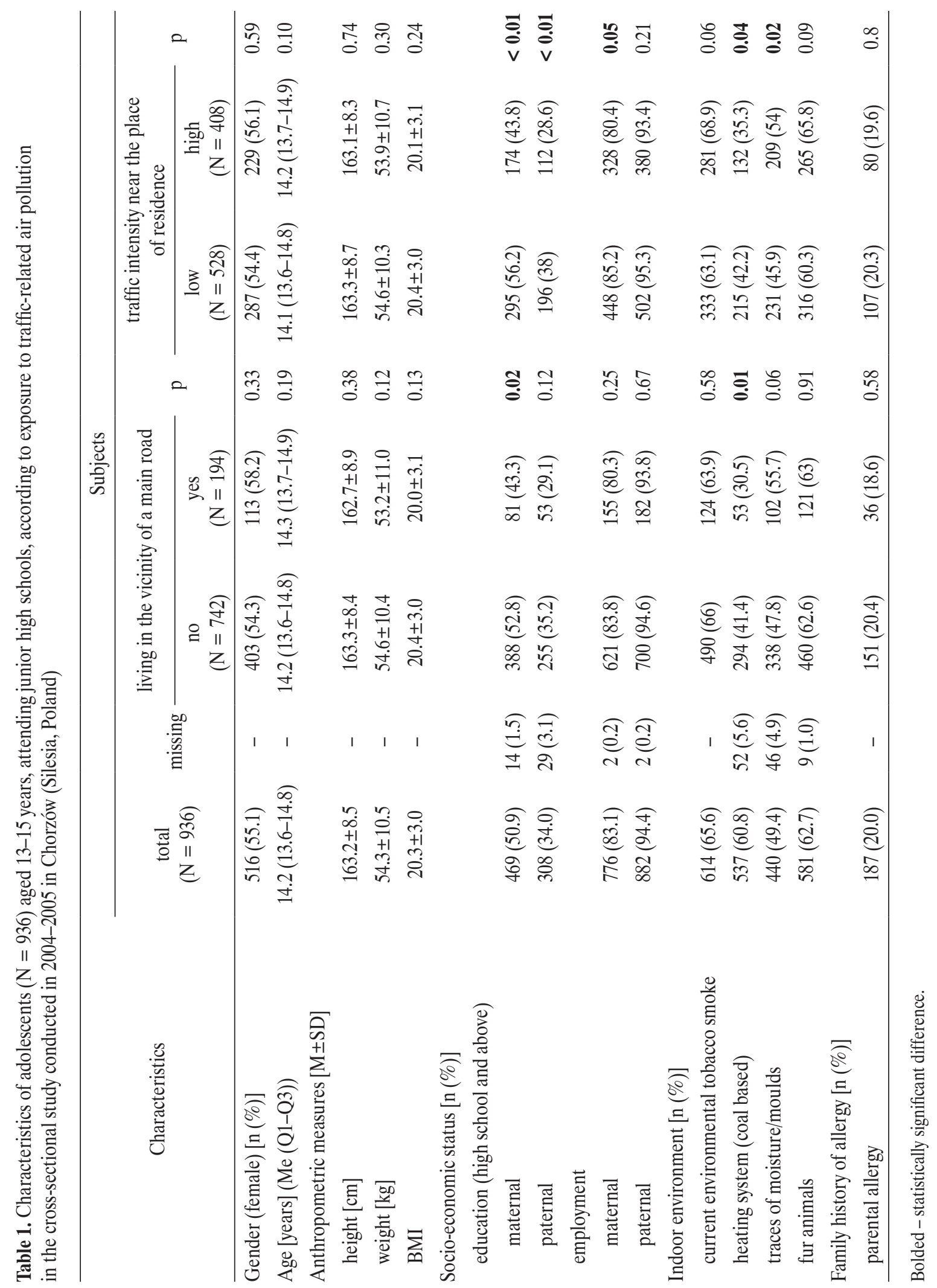




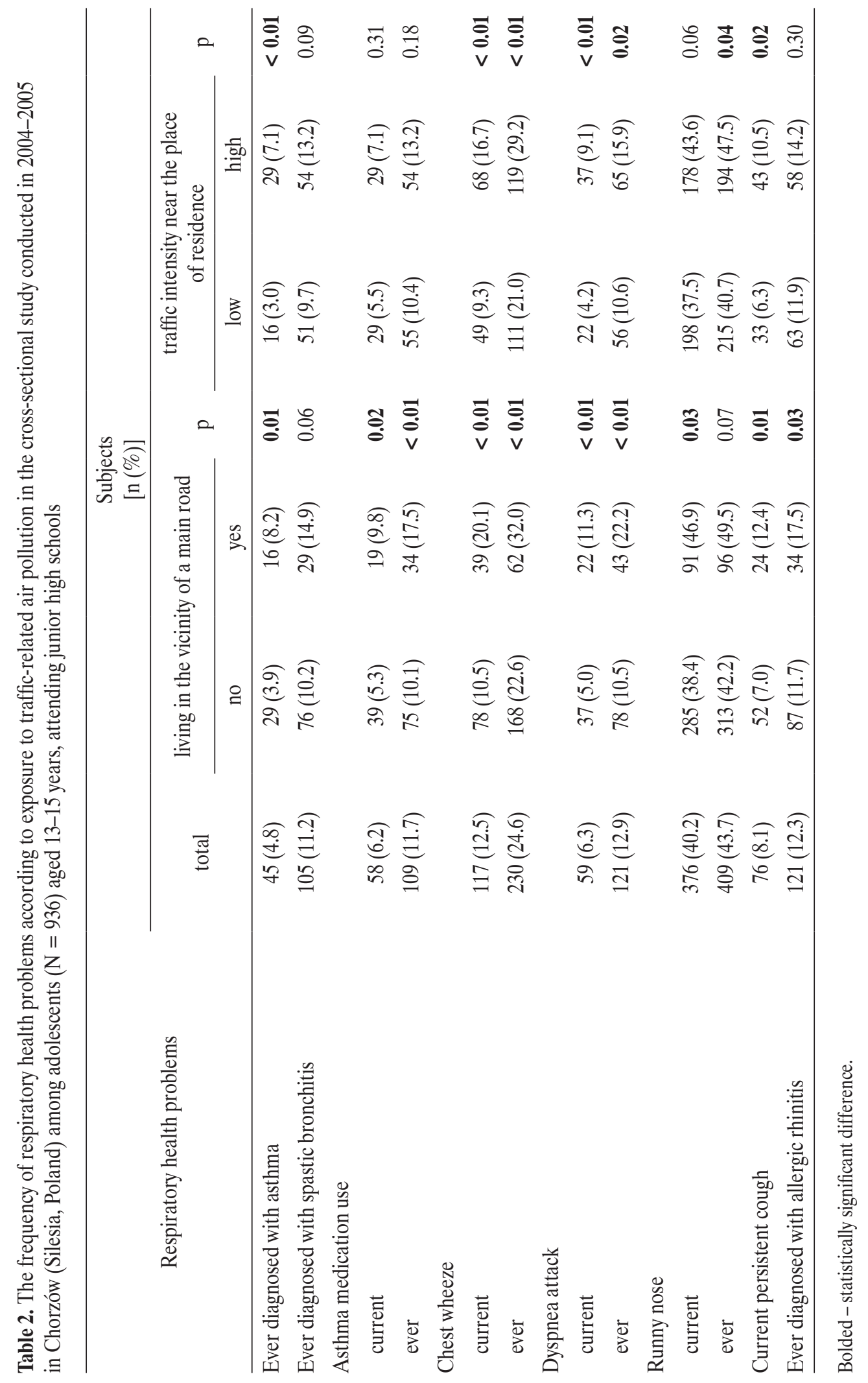


Table 3. Lung function and skin prick tests according to exposure to traffic-related air pollution $(\mathrm{N}=936)$ in the cross-sectional study conducted in 2004-2005 in Chorzów (Silesia, Poland) among adolescents ( $\mathrm{N}=936$ ) aged 13-15 years, attending junior high schools

\begin{tabular}{|c|c|c|c|c|c|c|c|}
\hline \multirow{3}{*}{ Variable } & \multicolumn{7}{|c|}{ Subjects } \\
\hline & \multirow[t]{2}{*}{ total } & \multicolumn{2}{|c|}{ living in the vicinity of a main road } & \multirow[t]{2}{*}{$\mathrm{p}$} & \multicolumn{2}{|c|}{$\begin{array}{l}\text { traffic intensity near the place } \\
\text { of residence }\end{array}$} & \multirow[t]{2}{*}{$\mathrm{p}$} \\
\hline & & no & yes & & low & high & \\
\hline \multicolumn{8}{|l|}{ Lung function $(\mathrm{M} \pm \mathrm{SD})$} \\
\hline $\mathrm{FVC}[1]$ & $3.62 \pm 0.72$ & $3.63 \pm 0.71$ & $3.59 \pm 0.77$ & 0.48 & $3.62 \pm 0.71$ & $3.62 \pm 0.74$ & 0.91 \\
\hline $\mathrm{FEV}_{1}[1]$ & $3.19 \pm 0.62$ & $3.20 \pm 0.61$ & $3.17 \pm 0.65$ & 0.51 & $3.20 \pm 0.62$ & $3.19 \pm 0.62$ & 0.81 \\
\hline$\% \mathrm{FEV}_{1}$ & $88.70 \pm 7.90$ & $88.61 \pm 7.75$ & $89.06 \pm 8.45$ & 0.48 & $88.78 \pm 7.94$ & $88.61 \pm 7.86$ & 0.76 \\
\hline $\mathrm{FEV}_{1} / \mathrm{FVC}[\%]$ & $88.57 \pm 7.34$ & $88.55 \pm 7.40$ & $88.63 \pm 7.11$ & 0.90 & $88.70 \pm 7.30$ & $88.40 \pm 7.39$ & 0.55 \\
\hline $\operatorname{PEF}[1 / \mathrm{s}]$ & $6.11 \pm 1.29$ & $6.11 \pm 1.27$ & $6.11 \pm 1.35$ & 0.99 & $6.14 \pm 1.30$ & $6.07 \pm 1.27$ & 0.36 \\
\hline \multicolumn{8}{|l|}{$\operatorname{MEF}[1 / \mathrm{s}]$} \\
\hline $\mathrm{MEF}_{25}$ & $5.54 \pm 1.24$ & $5.54 \pm 1.23$ & $5.58 \pm 1.25$ & 0.68 & $5.59 \pm 1.26$ & $5.49 \pm 1.21$ & 0.25 \\
\hline $\mathrm{MEF}_{50}$ & $4.17 \pm 1.05$ & $4.17 \pm 1.05$ & $4.14 \pm 1.05$ & 0.72 & $4.18 \pm 1.07$ & $4.15 \pm 1.02$ & 0.60 \\
\hline $\mathrm{MEF}_{75}$ & $2.27 \pm 0.79$ & $2.29 \pm 0.80$ & $2.20 \pm 0.76$ & 0.16 & $2.29 \pm 0.82$ & $2.25 \pm 0.76$ & 0.44 \\
\hline $\mathrm{MEF}_{25-75}$ & $3.72 \pm 0.97$ & $3.73 \pm 0.97$ & $3.67 \pm 0.98$ & 0.44 & $3.72 \pm 0.98$ & $3.72 \pm 0.95$ & 0.97 \\
\hline \multicolumn{8}{|l|}{ Prick tests [n (\%)] } \\
\hline any antigen & $441(47.1)$ & $351(47.3)$ & $90(46.4)$ & 0.82 & $251(47.5)$ & $190(46.6)$ & 0.77 \\
\hline mixed grass pollen & $205(21.9)$ & $159(21.4)$ & $46(23.7)$ & 0.49 & $116(22.0)$ & $89(21.8)$ & 0.95 \\
\hline mixed weed pollen & $164(17.5)$ & $129(17.4)$ & $35(18)$ & 0.83 & $94(17.8)$ & $70(17.2)$ & 0.80 \\
\hline Betula alba & $77(8.2)$ & $59(8.0)$ & $18(9.3)$ & 0.55 & $48(9.1)$ & $29(7.1)$ & 0.27 \\
\hline Corylus avellana & $61(6.5)$ & $48(6.5)$ & $13(6.7)$ & 0.91 & $34(6.4)$ & $27(6.6)$ & 0.91 \\
\hline Alternaria tenuis & $63(6.7)$ & $47(6.3)$ & $16(8.2)$ & 0.34 & $35(6.6)$ & $28(6.9)$ & 0.89 \\
\hline Cladosporium herbarum & $26(2.8)$ & $15(2.0)$ & $11(5.7)$ & 0.01 & $14(2.7)$ & $12(2.9)$ & 0.79 \\
\hline Aspergillus fumigatus & $17(1.8)$ & $12(1.6)$ & $5(2.6)$ & 0.37 & $9(1.7)$ & $8(2.0)$ & 0.77 \\
\hline house dust mites & $289(30.9)$ & $225(30.3)$ & $64(33)$ & 0.47 & $157(29.7)$ & $132(32.4)$ & 0.39 \\
\hline flour mites & $249(26.6)$ & $199(26.8)$ & $50(25.8)$ & 0.77 & $141(26.7)$ & $108(26.5)$ & 0.94 \\
\hline Acarus siro & $140(15)$ & $112(15.1)$ & $28(14.4)$ & 0.82 & $79(15.0)$ & $61(15)$ & 1.00 \\
\hline Tyrophagus putrescentiae & $108(11.5)$ & $85(11.5)$ & $23(11.9)$ & 0.88 & $57(10.8)$ & $51(12.5)$ & 0.42 \\
\hline Lepidoglyphus destructor & $106(11.3)$ & 79 (10.6) & $27(13.9)$ & 0.20 & $58(11.0)$ & 48 (11.8) & 0.71 \\
\hline cockroach & $51(5.5)$ & $39(5.3)$ & $12(6.2)$ & 0.61 & $29(5.5)$ & $22(5.4)$ & 0.95 \\
\hline dogs' fur & $50(5.3)$ & $36(4.9)$ & $14(7.2)$ & 0.19 & $26(4.9)$ & $24(5.9)$ & 0.52 \\
\hline cats' fur & $90(9.6)$ & $65(8.8)$ & $25(12.9)$ & 0.08 & $44(8.3)$ & $46(11.3)$ & 0.13 \\
\hline
\end{tabular}

$\mathrm{FEV}_{1}$ - forced expiratory volume in $1 \mathrm{~s} ; \% \mathrm{FEV}_{1}$ - percent predicted $\mathrm{FEV}_{1} ; \mathrm{FEV}_{1} / \mathrm{FVC}$ - ratio of $\mathrm{FEV}_{1}$ to $\mathrm{FVC} ; \mathrm{FVC}$ - forced vital capacity; MEF - mid-expiratory flow; PEF - peak expiratory flow.

Bolded - statistically significant difference. 
frequent in children living within the vicinity of a main road than in children living farther from a main road (5.7\% vs. $2.0 \%$, respectively; $\mathrm{p}=0.01$ ).

The authors performed multivariable logistic regression to assess the association between selected adverse health effects and the surrogates of exposure to traffic-related air pollution, with adjustment to the following confounders: gender, BMI, maternal employment, exposure to environmental tobacco smoke at home, type of heating, traces of moisture or moulds in the place of residence, and parental allergy (Tables 4 and 5). A higher prevalence of asthma, wheezes, dyspnea attack, and allergic rhinitis remained statistically significant in children living in the vicinity of a main road, while asthma, wheezes, and dyspnea attack remained statistically significant among children living in the area with high traffic intensity, after adjustment for confounders. Wheezes were more common in boys than in girls. Higher BMI was related to a more frequent diagnosis of asthma, spastic bronchitis and allergic rhinitis. Exposure to ETS at home was associated with a higher prevalence of spastic bronchitis, ever experienced wheezes, and dyspnea attack. Asthma and spastic bronchitis, as well as wheezes and dyspnea attack, were more frequent in children living in houses with the coal-based heating system. Traces of moisture or moulds in the place of residence were associated with a higher prevalence of ever experienced wheezes and runny nose. Additionally, children were more likely to have dyspnea attack or runny nose, and allergic rhinitis, when their parents declared allergy.

\section{DISCUSSION}

Public interest on the impact of ambient air quality on the population health, especially on the respiratory system in children, leads to many protests in Poland each year. Current data from the European Environment Agency (EEA) indicate that a significant share of fine dust, nitrogen oxides, ozone and carbon monoxide in air pollution is related to car traffic [36]. It is not without significance that traffic emission also contributes to polycyclic aromatic hydrocarbons (PAHs) pollution, including benzo(a)pyrene, which has a higher concentration in Poland [36]. The best exposure measurements are necessary to assess the causal relationship between the observed health phenomena and exposure to this risk factor, but in the case of a lack of direct or individual measurements of such exposure, it is possible to use an indirect route. In environmental epidemiology studies, it is common to use the distance to the place of residence from sources of hazard pollutant emissions, including roads with high traffic intensity, as an exposure measure [37]. Recent studies have indicated that higher exposure to carbon monoxide, fine particulate matter or black smoke, which are typical ambient air pollutants from transportation, affects people living in the vicinity of roads with heavy traffic in the Upper Silesian industrial zone [21].

The aim of the study was to assess the prevalence of respiratory diseases and disorders, as well as lung functions, in adolescents living in the vicinity of main roads in one of the biggest cities in the Silesian Agglomeration.

The obtained results suggest that a indirect measurement of exposure, expressed by the declared place of residence in the vicinity of a main road or a road with high intensity traffic, could be useful to describe the risk of being ever diagnosed with asthma, and chest wheeze or dyspnea attack being ever declared by parents, among children living in Chorzów (Tables 4 and 5). Moreover, the frequency of all the health outcomes presented in Table 2 was higher in those adolescents who lived close to a main road or a road with a high density of traffic intensity. These results are consistent with earlier data from the Upper Silesian region [21], as well as with other published observations, where self-reported data of exposure to traffic-related air pollution were also used [38-42].

A recent study has indicated that analyses of the relationship between pro-inflammatory effects of ambient air pollution and asthma should be based on the concentration of 


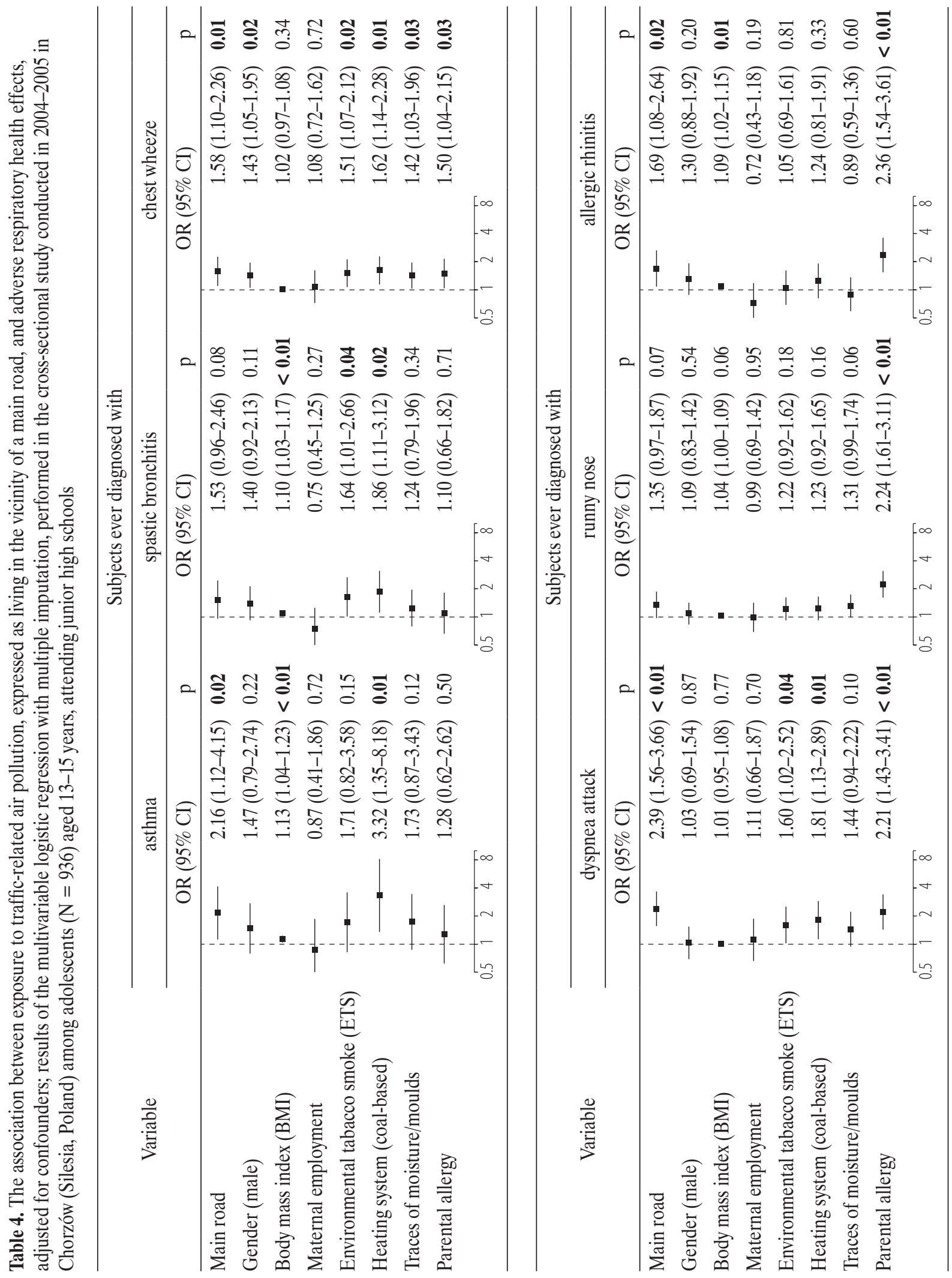




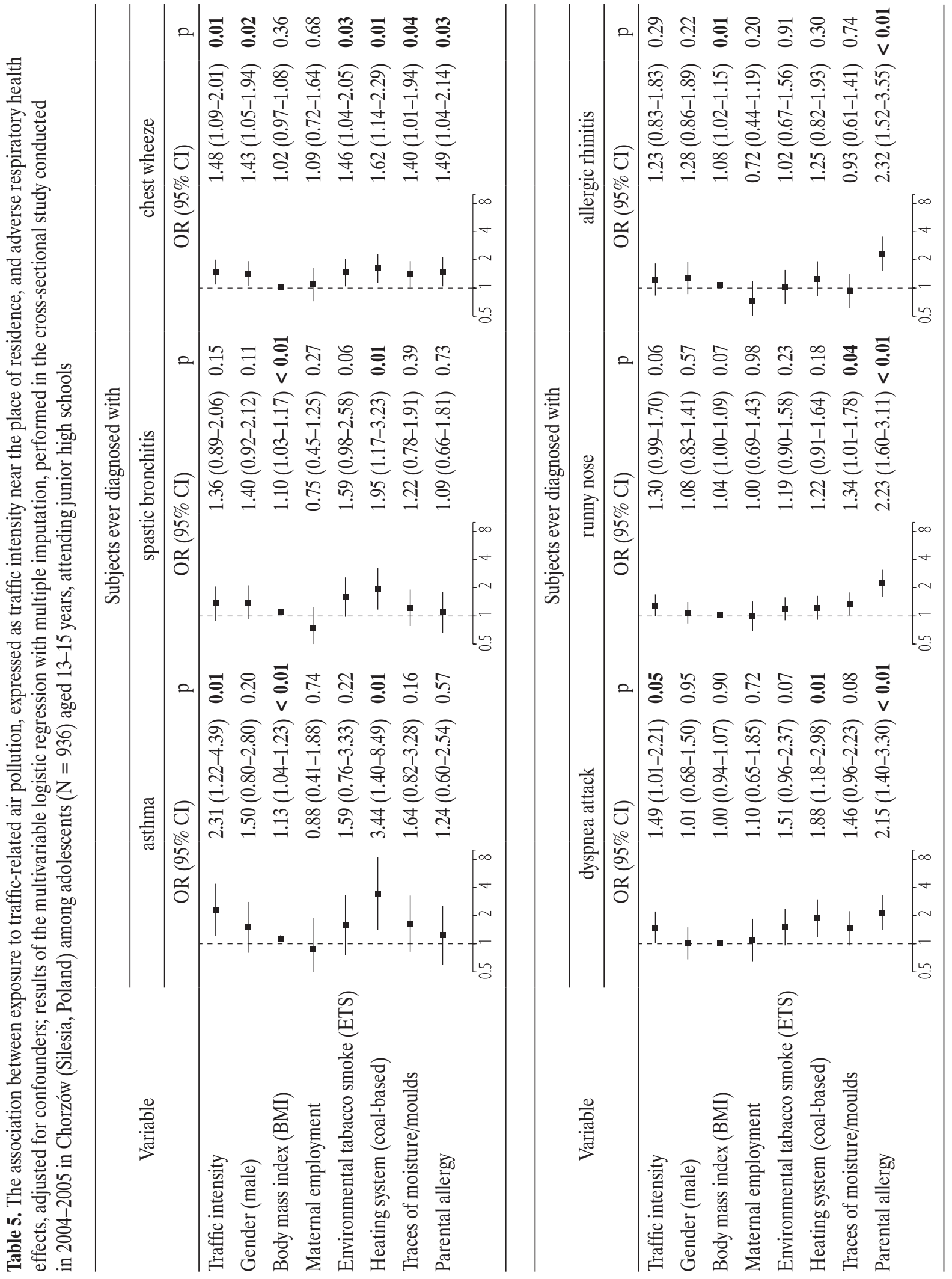


total emission from transportation, rather than on individual pollutants like PM (particulate matter) or PAHs [43]. Moreover, results of the ESCAPE study have confirmed the deleterious effect of air pollution on asthma incidence in adults [44]. It is worth mentioning that cohort studies have reported no significant association between air pollution exposure and childhood asthma prevalence in $5 \mathrm{Eu}-$ ropean birth cohorts [45], and they do not show a consistent association between chronic bronchitis symptoms and current traffic-related air pollution in adult European populations [46].

Unlike other research studies [47-50], the results presented by the authors did not confirm a statistically significant association between residing in the vicinity of the area with intense traffic and lung function indices, or the frequency of positive skin prick tests, in the studied children, except Cladosporium herbarum (Table 3). On the one hand, these findings could be explained by the labile course of asthma in young people and the fact that the examination of lung functions was performed only once. Likewise, it cannot be excluded that the observed elevated frequencies of adverse respiratory health effects in children living close to the main road were due to over-reporting of traffic intensity [51,52]. An important determinant of a child's health status could be the socio-economic status of his/her family, including the level of parental education or employment [53]. Results of a simple analysis suggested that a higher level of maternal and paternal education was statistically significantly associated with lower environmental exposure in children (traffic-related air pollution). However, the multivariable analysis did not confirm a significant association between the available socio-economic status factors and health outcomes in children.

There are some limitations of the study, the first being that cross-sectional design has known limits [54,55]. Moreover, due to the lack of direct traffic measurements in the Chorzów city, additional bias could be introduced by the use of self-reported exposure to traffic-related air pollu- tion $[51,52]$. It is worth mentioning that, according to the data provided by the general traffic measure in Poland for the year 2005, the average daily traffic on national roads in the Silesian Voivodeship was 13 433, and it was mainly (70\%) the passenger car traffic [13]. Consequently, the low response rate $(25 \%)$ may be an issue. People with respiratory health symptoms are more likely to participate in such surveys [56], which could cause self-selection bias towards a higher prevalence of the analyzed respiratory diseases and disorders. Interestingly, research conducted in Norway showed a similar prevalence of physician-diagnosed asthma in responders and non-responders, while the prevalence of chronic cough and asthma medication use was overestimated [57]. Nevertheless, no analysis of non-responders was possible in this study. Further bias, related to the potential reduction in the number of analyzed observations caused by missing data, was diminished by the use of multiple imputation method in the logistic regression analysis.

It should be noted that the use of indirect methods of the specification of exposure to traffic-related ambient air pollution, like the vicinity of a main road or traffic intensity, to assess the potential adverse health effects, may be useful in documenting the influence of road transport on the children's respiratory tract. A questionnaire addressed to parents may be used to select a group of children for whom the clinical assessment of the respiratory status should be made to unambiguously assess the relationship between traffic and their respiratory health.

\section{CONCLUSIONS}

Children living in the vicinity of main roads, or within the area characterized by high traffic flow, have been more frequently diagnosed with asthma or other adverse respiratory tract symptoms. The data presented in this study have not confirmed the statistically significant relation between the studied surrogates of exposure to traffic-related air pollution and spirometry indices, or the prevalence of 
positive skin prick tests. The vicinity of a main road, as well as traffic intensity, may be useful in assessing the relationship between road transport and potential respiratory health problems among exposed inhabitants.

\section{ACKNOWLEDGMENTS}

The authors would like to thank Dr. Alexander Lowe for his help to correct the final submission draft.

\section{REFERENCES}

1. Bousquet J, Khaltaev N. Global surveillance, prevention and control of chronic respiratory diseases: a comprehensive approach [Internet]. WHO Regional Office for Europe; 2007 [cited 2018 Mar 27]. Available from: http://apps.who.int/iris/ bitstream/10665/43776/1/9789241563468_eng.pdf.

2. Dockery DW, Speizer FE, Stram DO, Ware JH, Spengler JD, Ferris BG. Effects of inhalable particles on respiratory health of children. Am Rev Respir Dis. 1989;139(3):587-94, https:// doi.org/10.1164/ajrccm/139.3.587.

3. Schwartz J. Lung function and chronic exposure to air pollution: a cross-sectional analysis of NHANES II. Environ Res. 1989;50(2):309-21, https://doi.org/10.1016/s0013-9351(89)80 012-x.

4. Jędrychowski W, Flak E, Mróz E. The adverse effect of low levels of ambient air pollutants on lung function growth in preadolescent children. Environ Health Perspect. 1999;107(8): 669-74, https://doi.org/10.1289/ehp.99107669.

5. Peters JM, Avol E, Gauderman WJ, Linn WS, Navidi W, London SJ, et al. A study of twelve Southern California communities with differing levels and types of air pollution. II. Effects on pulmonary function. Am J Respir Crit Care Med. 1999;159(3):768-75, https://doi.org/10.1164/ajrccm.159.3.9804144.

6. Horak F, Studnicka M, Gartner C, Spengler JD, Tauber E, Urbanek R, et al. Particulate matter and lung function growth in children: a 3-yr follow-up study in Austrian schoolchildren. Eur Respir J. 2002;19(5):838-45, https://doi.org/10.1183/0903 1936.02.00512001.
7. Gauderman WJ, Avol E, Gilliland F, Vora H, Thomas D, Berhane K, et al. The effect of air pollution on lung development from 10 to 18 years of age. N Engl J Med. 2004; 351(11):1057-67, https://doi.org/10.1056/nejmoa040610.

8. Li S, Williams G, Jalaludin B, Baker P. Panel studies of air pollution on childrens' lung function and respiratory symptoms: a literature review. J Asthma. 2012;49(9):895-910, https://doi.org/10.3109/02770903.2012.724129.

9. Fuertes E, Bracher J, Flexeder C, Markevych I, Klümper C, Hoffmann B, et al. Long-term air pollution exposure and lung function in 15 year-old adolescents living in an urban and rural area in Germany: The GINIplus and LISAplus cohorts. Int J Hyg Environ Health. 2015;218(7):656-65, https:// doi.org/10.1016/j.ijheh.2015.07.003.

10. Gehring U, Gruzieva O, Agius RM, Beelen R, Custovic A, Cyrys J, et al. Air pollution exposure and lung function in children: the ESCAPE project. Environ Health Perspect. 2013;121(11-12):1357-64, https://doi.org/10.1289/ehp. 1306770.

11. European Environment Agency. The European environment - state and outlook 2015: synthesis report [Internet]. Copenhagen: 2015 [cited 2018 Mar 27]. Available from: https://www.eea.europa.eu/soer-2015/synthesis/report/action-download-pdf.

12. Chafe Z, Brauer M, Héroux ME, Klimont Z, Lanki T, Salonen RO, et al. Residential heating with wood and coal: health impacts and policy options in Europe and North America. WHO Regional Office for Europe; 2015.

13. Opoczyński K. [General traffic measure 2005]. Warsaw: General Directorate for National Roads and Highways; 2006. Polish.

14. Van Vliet P, Knape M, de Hartog J, Janssen N, Harssema H, Brunekreef B. Motor vehicle exhaust and chronic respiratory symptoms in children living near freeways. Environ Res. 1997;74(2):122-32, https://doi.org/10.1006/enrs.1997.3757.

15. Künzli N, Kaiser R, Medina S, Studnicka M, Chanel O, Filliger P, et al. Public-health impact of outdoor and traffic-related air pollution: a European assessment. Lancet. 
2000;356(9232):795-801, https://doi.org/10.1016/s0140-6736 (00)02653-2.

16. Brauer M, Hoek G, Van Vliet P, Meliefste K, Fischer PH, Wijga A, et al. Air pollution from traffic and the development of respiratory infections and asthmatic and allergic symptoms in children. Am J Respir Crit Care Med. 2002;166(8): 1092-8, https://doi.org/10.1164/rccm.200108-007oc.

17. Gauderman WJ, Avol E, Lurmann F, Kuenzli N, Gilliland F, Peters J, et al. Childhood asthma and exposure to traffic and nitrogen dioxide. Epidemiology. 2005;16(6):737-43, https:// doi.org/10.1097/01.ede.0000181308.51440.75.

18. McConnell R, Berhane K, Yao L, Jerrett M, Lurmann F, Gilliland F, et al. Traffic, susceptibility, and childhood asthma. Environ Health Perspect. 2006;114(5):766-72, https://doi. org/10.1289/ehp.8594.

19. Kim JJ, Huen K, Adams S, Smorodinsky S, Hoats A, Malig $\mathrm{B}$, et al. Residential traffic and childrens' respiratory health. Environ Health Perspect. 2008;116(9):1274-9, https://doi.org/10.1289/ehp.10735.

20. McConnell R, Islam T, Shankardass K, Jerrett M, Lurmann F, Gilliland F, et al. Childhood incident asthma and traffic-related air pollution at home and school. Environ Health Perspect. 2010;118(7):1021-6, https://doi.org/10.1289/ehp.0901232.

21. Skrzypek M, Zejda JE, Kowalska M, Czech EM. Effect of residential proximity to traffic on respiratory disorders in school children in upper Silesian Industrial Zone, Poland. Int J Occup Med Environ Health. 2013;26(1):83-91, https:// doi.org/10.2478/s13382-013-0078-2.

22. Kim HH, Lee CS, Yu SD, Lee JS, Chang JY, Jeon JM, et al. Near-Road Exposure and Impact of Air Pollution on Allergic Diseases in Elementary School Children: A Cross-Sectional Study. Yonsei Med J. 2016;57(3):698-713, https://doi. org/10.3349/ymj.2016.57.3.698.

23. English P, Neutra R, Scalf R, Sullivan M, Waller L, Zhu L. Examining associations between childhood asthma and traffic flow using a geographic information system. Environ Health Perspect. 1999;107(9):761-7, https://doi.org/10.2307/ 3434663.
24. Oftedal B, Brunekreef B, Nystad W, Nafstad P. Residential outdoor air pollution and allergen sensitization in schoolchildren in Oslo, Norway. Clin Exp Allergy. 2007;37(11):163240, https://doi.org/10.1111/j.1365-2222.2007.02823.x.

25. Oftedal B, Nystad W, Brunekreef B, Nafstad P. Long-term traffic-related exposures and asthma onset in schoolchildren in Oslo, Norway. Environ Health Perspect. 2009;117(5):83944, https://doi.org/10.1289/ehp.11491.

26. WHO Regional Office for Europe. Contaminated sites and health [Internet]. Copenhagen: 2013 [cited 2018 Mar 27]. Available from: http://www.euro.who.int/_data/assets/pdf_ file/0003/186240/e96843e.pdf.

27. Opoczyński K. [General traffic measure 2015]. Warsaw: General Directorate for National Roads and Highways; 2016. Polish.

28. Brożek G, Lawson J, Szumilas D, Zejda JE. Increasing prevalence of asthma, respiratory symptoms, and allergic diseases: Four repeated surveys from 1993-2014. Resp Med.2015;109(8):982-90,https://doi.org/10.1016/j.rmed.2015. 05.010.

29. Central Statistical Office of Poland [Internet]. Warsaw: The Office; 2017 [cited 2018 Mar 27]. The population density and indicators. Available from: https://bdl.stat.gov.pl.

30. Jaźwiec-Kanyion B, Złotkowska R, Zejda JE. [Reproducibility assessment of the questionnaire of respiratory symptoms in children]. Pneumol Alergol Pol. 1998;66:56-63, https:// doi.org/10.1097/00001648-199807001-00210. Polish.

31. Jaźwiec-Kanyion B, Zejda JE, Skiba M. [Reliability of the survey results in study of atopic children]. Med Srod. 2002;5(1):53-60. Polish.

32. Heinzerling L, Mari A, Bergmann KC, Bresciani M, Burbach G, Darsow U, et al. The skin prick test - European standards. Clin Transl Allergy. 2013;3(1):3-13, https://doi. org/10.1186/2045-7022-3-3.

33. Crilley LR, Lucarelli F, Bloss WJ, Harrison RM, Beddows DC, Calzolai G, et al. Source apportionment of fine and coarse particles at a roadside and urban background site in London during the 2012 summer ClearfLo campaign. 
Environ Pollut. 2017;220:766-78, https://doi.org/10.1016/j.en vpol.2016.06.002.

34. Segersson D, Eneroth K, Gidhagen L, Johansson C, Omstedt G, Nylén AE, et al. Health Impact of PM10, PM2.5 and Black Carbon Exposure Due to Different Source Sectors in Stockholm, Gothenburg and Umea, Sweden. Int J Environ Res Public Health. 2017;14(7):742-63, https://doi.org/ 10.3390/ijerph14070742.

35. Chen Q, Schwartz T, Duan N. Studying Missing Data Patterns Using a SAS Macro. Proceedings of the SAS Global Forum 2011 Conference; 2011 Apr 4-7; Las Vegas, US. Cary, NC: SAS Institute Inc; 2011. p. 339-43. Available from: http://support.sas.com/resources/papers/proceedings11/ 339-2011.pdf.

36. European Environment Agency. Air quality in Europe 2016 report [Internet]. Luxembourg; 2016 [cited 2018 Mar 27]. Available from: https://www.eea.europa.eu/publications/air-quality-in-europe-2016/download.

37. Nieuwenhuijsen MJ. Exposure Assessment in Occupational and Environmental Epidemiology. New York: Oxford University Press; 2003.

38. Brunekreef B, Stewart AW, Anderson HR, Lai CKW, Strachan DP, Pearce N, et al. Self-reported truck traffic on the street of residence and symptoms of asthma and allergic disease: a global relationship in ISAAC phase 3. Environ Health Perspect. 2009;117(11):1791-8, https://doi.org/10. 1289/ehp.0800467.

39. Migliore E, Berti G, Galassi C, Pearce N, Forastiere F, Calabrese $\mathrm{R}$, et al. Respiratory symptoms in children living near busy roads and their relationship to vehicular traffic: results of an Italian multicenter study (SIDRIA 2). Environ Health. 2009;8:27-43, https://doi.org/10.1186/1476-069x-8-27.

40. Middleton N, Yiallouros P, Nicolaou N, Kleanthous S, Pipis $\mathrm{S}$, Zeniou M, et al. Residential exposure to motor vehicle emissions and the risk of wheezing among 7-8 yearold schoolchildren: a city-wide cross-sectional study in Nicosia, Cyprus. Environ Health. 2010;9:28-45, https://doi. org/10.1186/1476-069x-9-28.
41. Vlaski E, Stavric K, Seckova L, Kimovska Hristova M, Isjanovska R. The self-reported density of truck traffic on residential streets and the impact on asthma, hay fever and eczema in young adolescents. Allergol Immunopathol (Madr). 2014;42(3):224-9, https://doi.org/10.1016/j.aller.2012.10.011.

42. Arnedo-Pena A, Romeu-Gracia MA, Bellido-Blasco JB, Meseguer-Ferrer N, Silvestre-Silvestre E, Conde F, et al. Incidence of allergic rhinitis in a cohort of young adults from 13-15 years old to 23-25 years old in Castellon (Spain). Allergol Immunopathol (Madr). 2017;45(3):251-7, https://doi. org/10.1016/j.aller.2016.08.012.

43. Guarnieri M, Balmes JR. Outdoor air pollution and asthma. Lancet. 2014;383(9928):1581-92, https://doi.org/10.1016/s01 40-6736(14)60617-6.

44. Jacquemin B, Siroux V, Sanchez M, Carsin AE, Schikowski T, Adam M, et al. Ambient air pollution and adult asthma incidence in six European cohorts (ESCAPE). Environ Health Perspect. 2015;123(6):613-21, https://doi.org/10.1289/ehp. 1408206.

45. Mölter A, Simpson A, Berdel D, Brunekreef B, Custovic A, Cyrys J, et al. A multicentre study of air pollution exposure and childhood asthma prevalence: the ESCAPE project. Eur Respir J. 2015;45(3):610-24, https://doi.org/ 10.1183/09031936.00083614.

46. Cai Y, Schikowski T, Adam M, Buschka A, Carsin AE, Jacquemin $\mathrm{B}$, et al. Cross-sectional associations between air pollution and chronic bronchitis: an ESCAPE meta-analysis across five cohorts. Thorax. 2014;69(11):1005-14, https://doi. org/10.1136/thoraxjnl-2013-204352.

47. Gauderman WJ, Vora H, McConnell R, Berhane K, Gilliland $\mathrm{F}$, Thomas D, et al. Effect of exposure to traffic on lung development from 10 to 18 years of age: a cohort study. Lancet. 2007;369(9561):571-7, https://doi.org/10.1016/s01406736(07)60037-3.

48. Oftedal B, Brunekreef B, Nystad W, Madsen C, Walker SE, Nafstad P. Residential outdoor air pollution and lung function in schoolchildren. Epidemiology. 2008;19(1):129-37, https://doi.org/10.1097/ede.0b013e31815c0827. 
49. Urman R, McConnell R, Islam T, Avol EL, Lurmann FW, Vora $\mathrm{H}$, et al. Associations of children's lung function with ambient air pollution: joint effects of regional and nearroadway pollutants. Thorax. 2014;69(6):540-7, https://doi. org/10.1136/thoraxjnl-2012-203159.

50. Rice MB, Rifas-Shiman SL, Litonjua AA, Oken E, Gillman MW, Kloog I, et al. Lifetime Exposure to Ambient Pollution and Lung Function in Children. Am J Respir Crit Care Med. 2016;193(8):881-8, https://doi.org/10.1164/ rccm.201506-1058oc.

51. Heinrich J, Gehring U, Cyrys J, Brauer M, Hoek G, Fischer P, et al. Exposure to traffic related air pollutants: self reported traffic intensity versus GIS modelled exposure. Occup Environ Med. 2005;62:517-23, https://doi.org/10.1136/ oem.2004.016766.

52. Kuehni CE, Strippoli MPF, Zwahlen M, Silverman M. Association between reported exposure to road traffic and respiratory symptoms in children: evidence of bias. Int J Epidemiol. 2006;35:779-86, https://doi.org/10.1093/ije/dyl022.
53. Taylor-Robinson DC, Pearce A, Whitehead M, Smyth R, Law C. Social inequalities in wheezing in children: findings from the UK Millennium Cohort Study. Eur Respir J. 2016;47:818-28, https://doi.org/10.1183/13993003.01117-2015.

54. Mann CJ. Observational research methods. Research design II: cohort, cross sectional, and case-control studies. Emerg Med J. 2003;20(1):54-60, https://doi.org/10.1136/ emj.20.1.54.

55. Setia MS. Methodology Series Module 3: Cross-sectional Studies. Indian J Dermatol. 2016;61(3):261-4, https://doi. org/10.4103/0019-5154.182410.

56. De Marco R, Verlato G, Zanolin E, Bugiani M, Drane JW. Nonresponse bias in EC Respiratory Health Survey in Italy. Eur Respir J. 1994;7(12):2139-45, https://doi.org/10.1183/09 031936.94.07122139.

57. Abrahamsen R, Svendsen MV, Henneberger PK, Gundersen GF, Torén K, Kongerud J, et al. Nonresponse in a crosssectional study of respiratory health in Norway. BMJ Open. 2016;6:e009912, https://doi.org/10.1136/bmjopen-2015-009912.

This work is available in Open Access model and licensed under a Creative Commons Attribution-NonCommercial 3.0 Poland License - http://creativecommons.org/ licenses/by-nc/3.0/pl/deed.en. 